\title{
AWARENESS OF WARNING SYMPTOMS, RISK FACTORS AND TREATMENT INCLUDING REHABILITATION OF STROKE AMONG THE HIGH RISK POPULATION
}

\author{
Khushbu Naik.
}

Assistant Professor, Department of Neurological \& psychosomatic disorders, Bharatimaiya College of Physiotherapy, Vesu Road, Surat, Gujarat, India.

\section{ABSTRACT}

Objective: To assess the awareness of warning symptoms, risk factors and treatment of stroke among the high risk population. This study mainly focus on how much awareness people have who are already on high risk for stroke.

Methodology: Sample size was 500. This hospital based survey done in urban population from. There is a threepart self administered questionnaire was used in this study which include demographic data, warning symptoms and treatment of stroke. Before filling the questionnaire duly consent was signed by patient, explained the questionnaire and then questions were asked during a one-to-one interview in the local vernacular language.

Conclusion: This study shows that the knowledge regarding the organ involved, warning symptoms and risk factors were comparatively better than other studies. Whereas the knowledge about treatment of stroke including rehabilitation was poor in this study.

KEY WORDS: Warning Symptoms, Risk Factors, Stroke, High Risk Population.

Address for correspondence: Dr.Khushbu Naik MPT, Assistant Professor, Department of Neurological \& psychosomatic disorders, Bharatimaiya College of Physiotherapy, Vesu Road, Surat, Gujarat, India. E-Mail: drdesai88@gmail.com

Access this Article online

Quick Response code

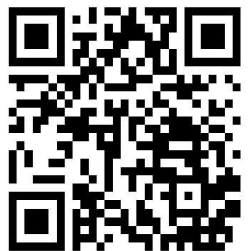

DOI: $10.16965 /$ ijpr.2018.182

\begin{tabular}{|c|c|c|}
\hline \multicolumn{3}{|c|}{ Journal Information } \\
\hline \multicolumn{2}{|c|}{ 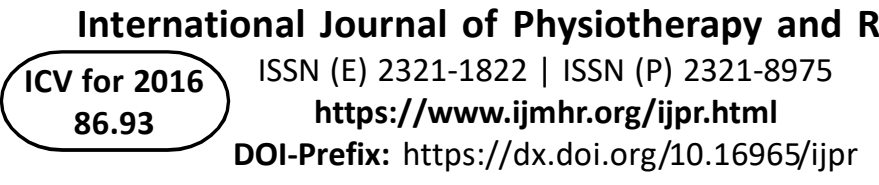 } & $(\mathrm{cc}) \mathrm{ET}-\mathrm{Mt}-\mathrm{SA}$ \\
\hline \multicolumn{3}{|c|}{ Article Information } \\
\hline $\begin{array}{l}\text { Received: } 26 \text { Oct } 2018 \\
\text { Peer Review: } 26 \text { Oct } 2018 \\
\text { Revised: None }\end{array}$ & \multicolumn{2}{|c|}{$\begin{array}{l}\text { Accepted: } 06 \text { Dec } 2018 \\
\text { Published (O): } 11 \text { Feb } 2019 \\
\text { Published (P): } 11 \text { Feb } 2019\end{array}$} \\
\hline
\end{tabular}

\section{INTRODUCTION}

Stroke in young poses a major health problem. WHO defines stroke as an event caused by the interruption of the blood supply to the brain, usually because a blood vessel bursts or is blocked by a clot. This cuts off the supply of oxygen and nutrients, causing damage to the brain tissue [1].

Stroke is the third commonest cause of mortality and the fourth leading cause Stroke in young poses a major health problem. WHO defines stroke as an event caused by the interruption of the blood supply to the brain, usually because a blood vessel bursts or is blocked by a clot. This cuts off the supply of oxygen and nutrients, causing damage to the brain tissue [1]. Stroke is the third commonest cause of mortality and the fourth leading cause $X$ stroke, including hypertension, high cholesterol, diabetes, heart disease and smoking can be prevented either through more healthy lifestyle choices or by medication [3]. The most common symptom of a stroke is sudden weakness or numbness of the face, arm, or leg, most often on one side of the body, occurring in $90 \%$ of the strokes. Other symptoms include confusion, difficulty speaking 
or understanding speech, difficulty seeing with one or both eyes, difficulty walking, dizziness, and loss of balance or coordination, severe headache with no known cause, fainting or unconsciousness [4].

In developing countries, planning for provision of much needed neurological rehabilitation services is important. Lack of definition of the size of the problem of disability resulting from neurological disability often hinders adequate planning and provision of resources and services. The article titled "Neurological Disorders and Barriers for Neurological Rehabilitation" in rural areas in Uttar Pradesh - a Cross-sectional Study" provides a useful preliminary insight into the surveillance and causes of neurological disorders as well as susceptible sections of the population in rural Uttar Pradesh [5]. In some studies, the age-standardized prevalence rates varied between 250 and 350 per 100,000 [6-12]. Except one study from the Parsi population whose demographic profile was distinct from that of the national mainstream [6]. Patients who recognize their increased risk for stroke and early warning symptoms are more likely to engage in stroke prevention practices than those who do not. In a previous hospital-based study, fewer than half of the stroke patients knew the signs, symptoms, or risk factors of a stroke. However, persons at risk often tend to underestimate the possibility of an adverse health event. This underestimation may be particularly significant when patients are currently without symptoms, the absolute risk of the adverse event is low, the adverse event is not imminent, and the patient lacks direct experience with the event in question [7-8]. Patients with greater than or equal to one clinical or behavioural risk factor have a further increased risk of stroke recurrence, and appropriate management of risk factors has been shown to be important for secondary prevention. Despite recent advances in stroke therapy, the public remains uninformed about strokes, and few stroke patients present to hospital in time to receive treatment [9].

Even in developed countries, like United States, Australia, South Korea and Canada, there is a recognized lack of knowledge in the community about established stroke risk factors and warning signs [10-12].
In the management of stroke, time of presentation to the hospital is important as delays often result in poor outcome. The longest phase of delay continues to be the time from symptom recognition to the decision to seek care, and it is in this phase that the most improvement could be achieved [13]. In order to control strokerelated morbidity and mortality, magnitude of awareness regarding symptoms and risk factors are necessary to evaluate.

Hence, this study intended to investigate awareness of warning symptoms, risk factors and treatment of stroke in high- risk population.

Aim of the Study: To assess the awareness of warning symptoms, risk factors and treatment of stroke among the high risk population.

\section{MATERIALS AND METHODS}

Source of data: The participants who are willing to participate in the study and who meet the eligibility criteria will be included in this study. These participants will be recruited from state of Karnataka and Gujarat.

\section{Sampling: Convenience sampling.}

\section{Sample size: 500}

Methods of collection of data:

Procedure: Subjects will be selected conviently for participation. Consent form will be duly signed from participants before filling up the Questionnaire.A questionnaire will be distributed among the participants who fulfill the inclusion criteria. The Questionnaire is a three part self-administered questionnaire. Part one includes the Demographic data of participants which include the name, age, sex, marital status, religion, education and economical status. Part two include the warning symptoms, risk factors and from where they got the knowledge of stroke. Also it covers whether they are told by any doctor that they are suffering from any of the risk factor. Third part includes the treatment with rehabilitation of stroke. Most of the questions are open-ended.

Materials Used: Consent form, Pen and Pad. Questionnaire.

Inclusion Criteria: Person who is suffering from hypertension, diabetic, any of the heart disease. Also who has habit of tobeco, alcohol and 
smoking. Obese person. Age more than $18 \mathrm{yrs}$. Person who able to following command.

Exclusion Criteria: People without any of the above condition. Who has previous stroke history.

\section{Data Analysis:}

Table 1: Demographic details of study participants

\begin{tabular}{|l|c|c|}
\hline Characteristic & Frequency & Percentage \\
\hline Sex & \multicolumn{2}{|l|}{} \\
Male & 277 & 55.4 \\
Female & 223 & 44.6 \\
Total & 500 & 100 \\
\hline Education & \multicolumn{2}{|c|}{} \\
Informal & 3 & 6 \\
Primary & 72 & 14.4 \\
Secondary & 241 & 48.2 \\
Post secondary & 184 & 36.8 \\
Total & 500 & 100 \\
\hline Occupation & \multicolumn{3}{|l|}{} \\
Govt/private & 187 & 37.4 \\
Proffesional & 125 & 25 \\
Housewife & 131 & 26.2 \\
Unemployed & 57 & 11.4 \\
Total & 500 & 100 \\
\hline
\end{tabular}

Table: 2: Characteristics of knowledge about organ involvement in stroke.

\begin{tabular}{|c|l|c|c|}
\hline Sr. No. & \multicolumn{1}{|c|}{ Characteristic } & Frequency & Percentage \\
\hline $\mathbf{1}$ & Don't know & 136 & 27.2 \\
$\mathbf{2}$ & Heart & 11 & 2.2 \\
$\mathbf{3}$ & Chest & 1 & 0.2 \\
$\mathbf{4}$ & Brain & 284 & 56.8 \\
$\mathbf{5}$ & Whole body & 68 & 13.6 \\
& Total & 500 & 500 \\
\hline
\end{tabular}

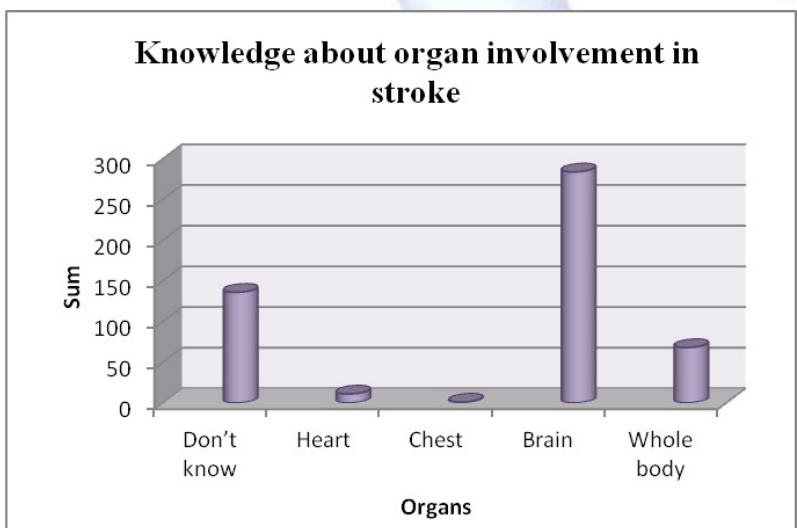

Table 3: Characteristic of subject's knowledge of stroke pathology.

\begin{tabular}{|c|l|c|c|}
\hline Sr. No. & Characteristics & Frequency & Percentage \\
\hline $\mathbf{1}$ & Occlusion of vessels & 57 & 11.4 \\
\hline $\mathbf{2}$ & Rupture of vessels & 147 & 29.4 \\
\hline $\mathbf{3}$ & Swelling & 0 & 0 \\
\hline $\mathbf{4}$ & Brain fever & 0 & 0 \\
\hline $\mathbf{5}$ & Collection of fluid & 0 & 0 \\
\hline
\end{tabular}

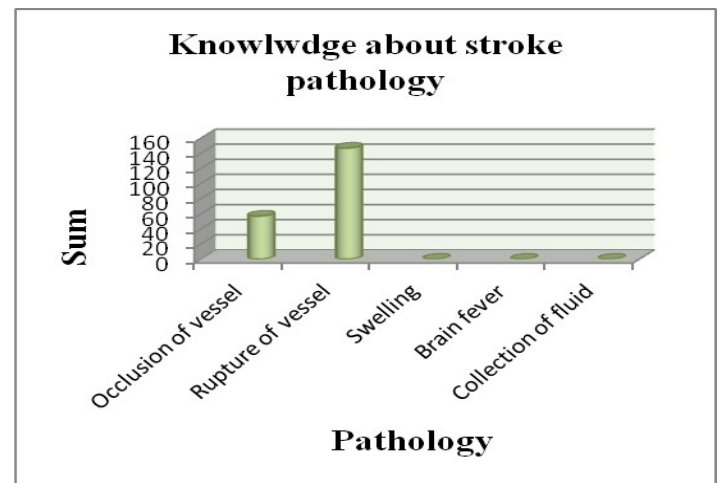

Table 4: Characteristic of knowledge of warning symptoms of stroke

\begin{tabular}{|c|l|c|c|}
\hline Sr. No. & \multicolumn{1}{|c|}{ Characteristics } & Frequency & Percentage \\
\hline $\mathbf{1}$ & Don't know & 101 & 20.2 \\
$\mathbf{2}$ & Numbness & 34 & 6.8 \\
$\mathbf{3}$ & Sudden paralysis of one side of body & 385 & 77 \\
$\mathbf{4}$ & Sudden tingling sessation & 14 & 2.8 \\
$\mathbf{5}$ & Sudden blurred vision, double vision & 34 & 6.8 \\
$\mathbf{6}$ & Difficulty in speaking & 54 & 10.8 \\
$\mathbf{7}$ & Loss of consciousness & 60 & 12 \\
$\mathbf{8}$ & Sudden loss of vision in one eye & 25 & 5 \\
$\mathbf{9}$ & Sudden headache & 90 & 18 \\
$\mathbf{1 0}$ & Sudden dizziness,loss of balance & 77 & 15.4 \\
$\mathbf{1 1}$ & Sudden fall & 121 & 24.2 \\
$\mathbf{1 2}$ & Slurred speech & 36 & 7.2 \\
\hline
\end{tabular}

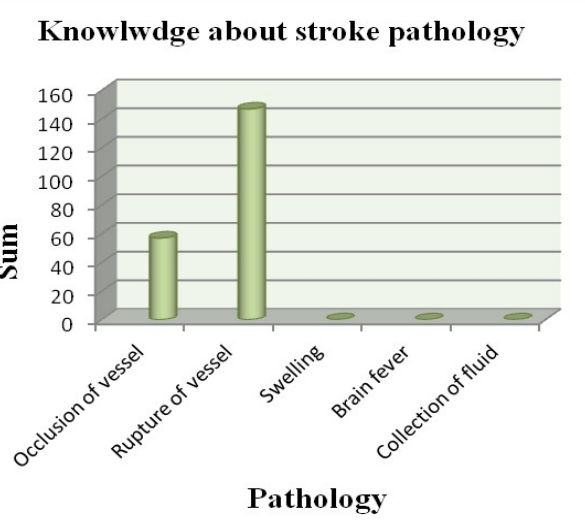

Table 5: Characteristic of knowledge of risk factors for stroke.

\begin{tabular}{|c|l|c|c|}
\hline Sr. No & Characteristic & Freqency & Percentage \\
\hline 1 & Don't know & 80 & 16 \\
2 & High B.P & 420 & 84 \\
3 & Diabetic & 327 & 65.4 \\
4 & High cholesterol & 136 & 27.2 \\
5 & Ciggarette smoking & 37 & 7.4 \\
6 & Sedentary life style & 46 & 9.2 \\
7 & Aging & 64 & 12.8 \\
8 & Alcohol & 26 & 5.2 \\
9 & Lack of exercise & 48 & 9.6 \\
10 & Others & 41 & 8.2 \\
11 & Heart disease & 127 & 25.4 \\
12 & Stress & 127 & 25.4 \\
13 & Obesity & 109 & 21.8 \\
14 & Hereditary & 31 & 6.2 \\
15 & Family history & 21 & 4.2 \\
16 & Bad diet & 21 & 4.2 \\
17 & Tobacco chewing & 10 & 2 \\
\hline
\end{tabular}




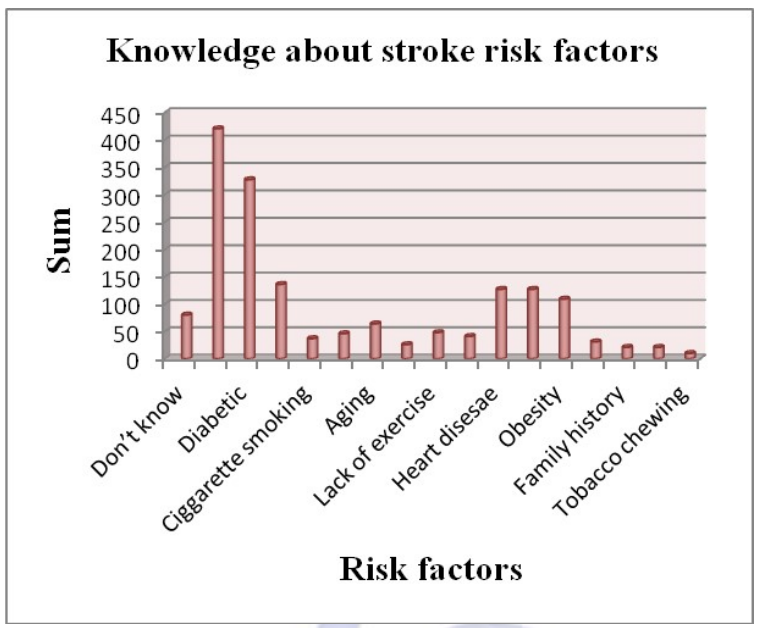

Table 6: Characteristic of different source of knowledge of stroke.

\begin{tabular}{|c|l|c|c|}
\hline Sr. No & \multicolumn{1}{|c|}{ Characteristics } & Frequency & Percentage \\
\hline $\mathbf{1}$ & Newspapers & 260 & 52 \\
\hline $\mathbf{2}$ & Friends/Relatives & 426 & 85.2 \\
\hline $\mathbf{3}$ & Radio/TV & 184 & 36.8 \\
\hline $\mathbf{4}$ & Doctors & 174 & 34.8 \\
\hline $\mathbf{5}$ & Medical books & 72 & 14.4 \\
\hline $\mathbf{6}$ & Patients with stroke & 123 & 24.6 \\
\hline $\mathbf{7}$ & Others & 44 & 8.8 \\
\hline $\mathbf{8}$ & Other health workers & 39 & 7.8 \\
\hline
\end{tabular}

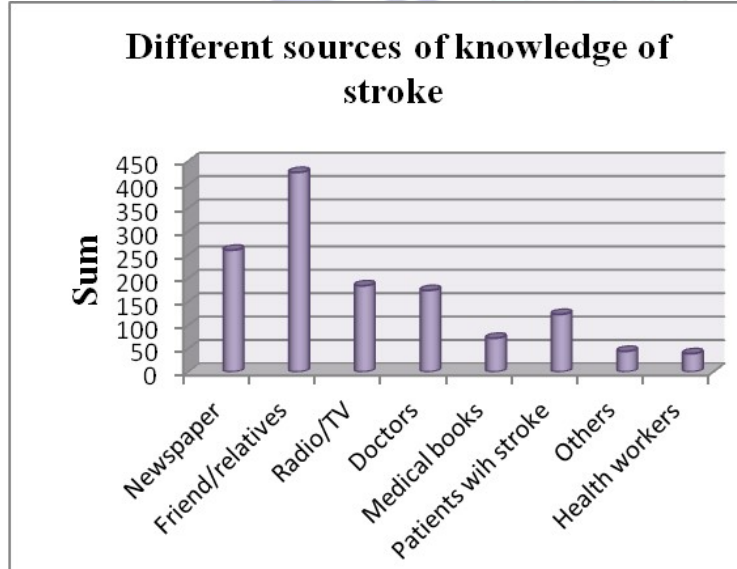

Different sources

Table 7: Respondent's reaction to stroke symptoms and knowledge about treatment.

\begin{tabular}{|l|c|c|}
\hline \multicolumn{1}{|c|}{ Action } & Frequency & Percentage \\
\hline Taken to the hospital & 457 & 91.4 \\
Buy medicine from shop & 2 & 0.4 \\
Faith healers & 0 & 0 \\
Wait and watch till symptoms subsides & 0 & 0 \\
Don't know & 41 & 8.2 \\
Knowledge about treatment & & \\
Aspirin & 3 & 0.6 \\
Blood thinning agent & 14 & 2.8 \\
BP control & 99 & 19.8 \\
Diabetic control & 54 & 10.8 \\
Surgery & 7 & 1.4 \\
Witchcraft & 1 & 0.2 \\
Prayers & 0 & 0 \\
Faith healers & 0 & 0 \\
Others & 7 & 1.4 \\
\hline
\end{tabular}

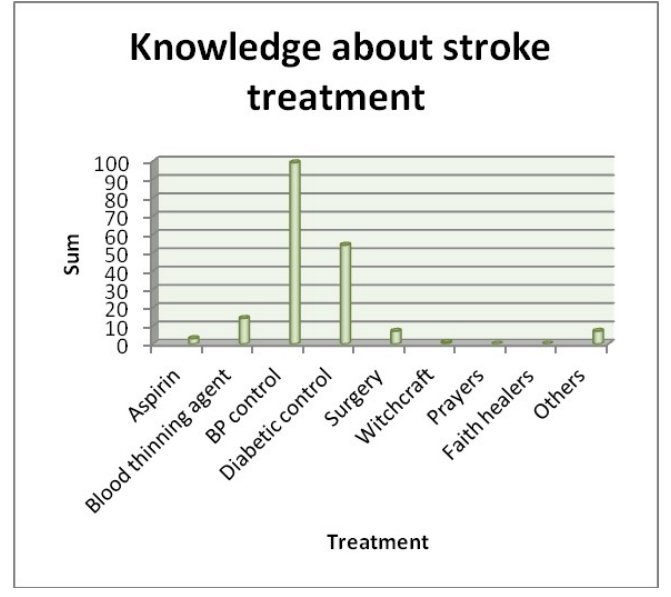

Table 8: Knowledge of rehabilitation treatment after stroke.

\begin{tabular}{|c|l|c|c|}
\hline Sr.No. & \multicolumn{1}{|c|}{ Characteristic } & Frequency & Percentage \\
\hline $\mathbf{1}$ & Stretching & 20 & 4 \\
$\mathbf{2}$ & Strengthening & 29 & 5.8 \\
$\mathbf{3}$ & Walking & 104 & 20.8 \\
$\mathbf{4}$ & Balance training & 77 & 15.4 \\
$\mathbf{5}$ & Co ordination exercise & 38 & 7.6 \\
$\mathbf{6}$ & Hand gripping exercise & 12 & 2.4 \\
$\mathbf{7}$ & Others & 26 & 5.2 \\
\hline
\end{tabular}

Knowledge about rehabilitation after stroke

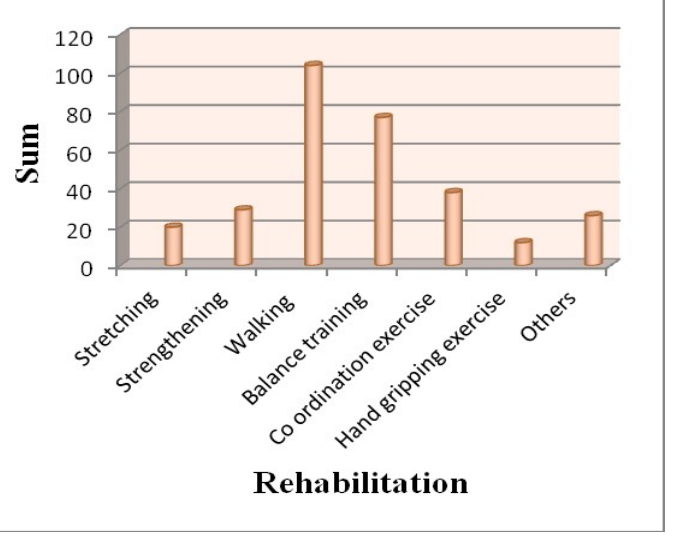

\section{DISCUSSION}

The purpose of the study was to know the knowledge of stroke warning symptoms, risk factors and treatment including rehabilitation among the high risk population from the different hospitals of Karnataka and Gujarat. The study was conducted in high risk population who were screened by physician/neurologist for high risk of stroke. Questions were asked through one-to-one interview in local language. No attempt was made to prompt the respondents by suggesting answers directly. Statistical analysis was performed using SPSS version 16 . Descriptive statistics were done to know the 
frequency and percentage of individual characteristic of all five hundred subjects. In this study, subject's knowledge about involved organ in stroke was comparatively higher than study done by Pandian et al. [14] Of five hundred subjects, two hundred and eighty four respondents (56.8\%) correctly identified the "Brain" as a affected organ in stroke, whereas in previous study the knowledge of involved organ was poor (45\%). Occlusion of a vessel as the cause of stroke was correctly stated by fifty-seven $(11.4 \%)$ of the respondents which is poor than previous study Pandian et al. [14] in which $30.8 \%$ respondents identified it correctly. One hundred and forty-seven (29.4\%) participants mentioned that rupture of vessel could lead to stroke.

The most common warning symptoms identified by subjects in this study was weakness of one side of body (77\%), which was comparable with other studies from Mosca L et al. [15] (66.4\%), Sung S. Kim et al. (70\%) and Kothari et al (50\%). One hundred and one (20.2\%) participants who did not know even a single warning symptoms was also comparable with other studies [16-18] Other symptoms which were identified by participants in our study were numbness of limb $6.8 \%$, slurred speech $7.2 \%$, difficulty in speaking $10.8 \%$, headache $18 \%$ dizziness $15.4 \%$ and blurred vision $6.8 \%$ which was shown to poor knowledge compared to other study conducted by the Gallup Organization for the National Stroke Association [19] in which symptoms listed by the respondents were, $31 \%$ listed numbness of the face, arm, or leg, $31 \%$ listed paralysis of the face, arm, or leg, $18 \%$ listed slurred speech, $18 \%$ listed difficulty speaking or understanding, $12 \%$ listed headaches, $10 \%$ listed dizziness, and $9 \%$ listed blurred vision or a loss of vision as symptoms of stroke [19]. The proportion of subjects who named "Hypertension" as a risk factor was $84 \%$ which was similar to previous studies.

The respondents who had positive answers for other risk factors, such as diabetic $65.4 \%$, high cholesterol $27.2 \%$, heart disease $25.4 \%$, stress $25.4 \%$ and obesity $21.8 \%$ were much lower as compared with other studies [16-18]. A majority of subjects heard about stroke in our study from the newspaper $52 \%$, through television $24 \%$ and through doctors $34.8 \%$ are similar to other study
[20], whereas newspaper sources identified by respondents was $42 \%$,television was $24 \%$ and through doctors was $29 \%$. A majority of the respondents (91.4\%) preferred to take a person to the hospital when they or someone close to them had experienced symptoms of stroke. In this study none of participants had an idea about Golden Window Period which is the important period after stroke for treatment. Physicians and family doctors should spread the awareness about immediate care of stroke. This is true for developing countries, where the number of neurologists available to any population is proportionately much less than that in developed countries.

The majority did not know about the appropriate treatment for stroke 63\%. Approximately $1.6 \%$ of them believed in indigenous treatment, including, oil massage, witchcraft, homeopathic and ayurvedic treatment which was poorer than previous study where the knowledge of indigenous treatment was $10.7 \%$. Only $0.6 \%$ respondents believed aspirin as a treatment of stroke which was poorer than previous studies [14], where respondent's response for aspirin was $7.4 \%$.

In this study there are two hundred and four (40.8\%) subjects don't know anything regarding rehabilitation treatment after stroke whereas rest of the subjects answered about the rehabilitation treatment after stroke. There is lack of public awareness about rehabilitation after stroke as a treatment. People in younger age groups have been shown to be more knowledgeable than older people prior to intervention with public health promotion campaigns and to remain more knowledgeable after the campaign [21]. However, there is evidence that television based advertising may contribute to a reduction in age-related differences in knowledge of stroke warning signs [19].

Our study addresses only the baseline public knowledge of stroke warning signs and risk factors. Educational programs must focus on risk factor modification and actions to take if stroke symptoms occur. Our data indicate that government must take sincere effort in spreading awareness to the general community (population prone to develop stroke and their relatives) about the risk factors, warning symptoms and 
emergency basic treatment for stroke. Government should also highlight the importance of golden window period which is important period after stroke. In this study knowledge of rehabilitation is also poor, so they should also educate the community regarding rehabilitation after stroke through some media sources. So that people may take more rational and beneficial health care decisions.

Limitations of the study and future suggestions: Future studies are needed which focus on community surveys including both rural and urban populations.

\section{CONCLUSION}

This hospital-based survey among the high risk population reveals an awareness of stroke warning signs, risk factors, treatment and rehabilitation comparable with studies from developed countries. The knowledge regarding the organ involved, warning symptoms and risk factors were comparatively better than other studies. This study was done in urban population, so high risk subjects might have been educated by the family doctor and physician regarding their risk factors and its complication; this could be one of the reasons behind good knowledge. Whereas the knowledge about treatment of stroke including rehabilitation was poor in this study. Considerable education is needed to increase the public's awareness of the warning signs and risk factors for stroke. Efforts should also be made to educate the public about modern concepts of stroke treatment and rehabilitation, so that people may make more rational and beneficial health care decisions.

\section{ACKNOWLEDGEMENTS}

Any accomplishment cannot be performed single handed but requires the efforts of many individuals. First of all, I am thankful to GOD who always blessed me and kept my faith inbuilt in me as a constant force of encouragement, support and trust. I am very much thankful to my P. G. Guide, T.JOSELEY SUNDERRAJ PANDIAN, ASSOCIATE PROFESSOR, Srinivas college of physiotherapy, Mangalore who has remained generous with his time and guided me with his resourceful knowledge. I thank Dr. DR.RAMPRASAD M. Professor and Principal
Srinivas College of Physiotherapy, Mangalore and DR. RAMA PRABHU K.R Associate Professor Srinivas College of Physiotherapy, Mangalore. I wish to express my gratitude thanks to my respectable professor DR. PITCHAIAH A. , DR. RAMA PRABHU K.R, DR. RAM ANAND \& DR. SRI DEVI, Srinivas College of Physiotherapy, Pandeshwar, Mangalore for his valuable guidance and keen interest shown in this dissertation work and without whom this work would have not taken shape. Finally, I am thankful to my husband, my parents, my brother, my in laws for always believing in me and encouraging me to achieve my goals.

\section{Conflicts of interest: None}

\section{REFERENCES}

[1]. WHO,"Stroke, Cerebrovascular accident" August 2010 http://www.who.int/topics/cerebrovascular accident/en/.

[2]. Manjari Tripathi1 and Deepti Vibha2. Stroke in Young in India. SAGE-Hindawi Access to Research Stroke Research and Treatment Volume 2011, Article ID 368629, 6 pages.

[3]. Samsa GP, Cohen SJ, Goldstein LB, Bonito AJ, Duncan PW, Enarson C, DeFriese GH, Horner RD, Matchar DB. Knowledge of risk among patients at increased risk for stroke. Stroke. 1997 May 1;28(5):916-21.

[4]. R Prakash Upadhyay. An Overview of the Burden of Non- Communicable Diseases in India. Iranian J Publ Health, 2012;41(3):1-8.

[5]. Kumar H, Gupta N. Neurological disorders and barriers for neurological rehabilitation in rural areas in Uttar Pradesh: A cross-sectional study. J Neurosci Rural Pract 2012;3:12-6.

[6]. N E Bharucha, E P Bharucha, A E Bharucha et al. Prevalence of stroke in the Parsi community of Bombay. Stroke. 1988;19:60-62.

[7]. Marcus B Nicol and Amanda G Thrift. Knowledge of risk factors and warning signs of stroke. Vascular Health and Risk Management 2005:1(2):137-147.

[8]. Hinkle J, Chanda R, Buchan A, Manoj A. awareness Of Stroke Risk And Symptoms In Diabetes Patients: this is a summary: the full paper can be accessed atnursingtimes. net. Nursing Times. 2008 Aug 5;104(31):32-3.

[9]. Judith Redfern, Chris McKevitt, Ruth Dundas et al. Behavioral Risk Factor Prevalence and Lifestyle Change After Stroke-A Prospective Study. Stroke. 2000;31:1877-1881.

[10]. Sung Sug Yoon, Richard F Heller, Christopher Levi et al. Knowledge and perception about stroke among an Australian urban Population. BMC Public Health 2001;1:14. 
[11]. Ying Zhang, James M.Galloway, Thomas K. Welty et al. Incidence and Risk Factors for Stroke in American Indians : The Strong Heart Study. Circulation. 2008;118:1577-1584.

[12]. Zarmeneh Aly,1 Kanza Abbas, 2 Syed Faraz Kazim et al. Awareness of stroke risk factors, signs and treatment in a Pakistani population. JPMA 2009;59:495.

[13]. Kolawole W Wahab, Peter O Okokhere, Asuwemhe $\mathrm{J}$ Ugheoke et al. Awareness of warning signs among suburban Nigerians at high risk for stroke is poor: A cross-sectional study. BMC Neurology 2008:8:18.

[14]. Jeyaraj D. Pandian, Ashish Jaison, Sukhbinder S. Deepak et al. Public Awareness of Warning Symptoms, Risk Factors, and Treatment of Stroke: in Northwest India. Stroke 2005;36:644-648.

[15]. Razdan S, Koul RL, Motta A, Kaul S. Cerebrovascular disease in rural Kashmir, India. Stroke. 1989;20:1691-1693.

[16]. Pancioli AM, Broderick J, Kothari R, Brott J, Tuchfarber A, Miller R, Khoury J, Jauch E. Public perception of stroke warning signs and knowledge of potential risk factors. JAMA. 1998;279:1288-1292.

[17]. Sug Yoon S, Heller RF, Levi C, Wiggers J, Fitzgerald PE. Knowledge of stroke risk factors, warning symptoms and treatment among an Australian urban population. Stroke. 2001; 32:1926 -1930.
[18]. Reeves MJ, Hogan JG, Rafferty AP. Knowledge of stroke risk factors and warning signs among Michigan adults. Neurology. 2002; 59:1547-1552.

[19]. National Stroke Association. Awareness and Knowledge of Stroke Prevention: A Study of Adults, 50 Years of Age and Over. Englewood, Colo: National Stroke Association; 1996.

[20]. Mosca L, Jones WK, King KB, Ouyang P, Redberg RF, Hill MN. Awareness, perception, and knowledge of heart disease risk and prevention among women in the United States. American Heart Association Women's Heart Disease and Stroke Campaign Task Force. Arch Fam Med. 2000;9:506-15.

[21]. Fogle CC, Oser CS, Troutman TP, McNamara M, Williamson AP, Keller M, McNamara S, Helgerson SD, Gohdes D, Harwell TS. Public education strategies to increase awareness of stroke warning signs and the need to call 911. J Public Health Management Practice. 2008; 14:E17-E22.

How to cite this article:

Khushbu Naik. AWARENESS OF WARNING SYMPTOMS, RISK FACTORS AND TREATMENT INCLUDING REHABILITATION OF STROKE AMONG THE HIGH RISK POPULATION. Int J Physiother Res 2019;7(1):2963-2969. DOI: 10.16965/ijpr.2018.182 